\title{
Progress in simulation research: an editorial introduction and overview
}

\author{
SJE Taylor ${ }^{1}$, S Robinson ${ }^{2}$ and RJ Paul ${ }^{1}$ \\ ${ }^{1}$ Brunel University, UK. ${ }^{2}$ Warwick University, UK
}

Simulation modelling, sometimes called computer simulation or just simulation, is a term that covers a wide range of processes, techniques and technologies. Although it is often considered the method of last resort, as simulations often take a long time to construct and are typically quite complex, simulation modelling has been used in decision support systems to analyse aspects of organisational process since the 1960s.

It has been over a decade since an issue of the Journal of Operational Research Society was dedicated to this subject. ${ }^{1}$ Since then simulation modelling has been well represented at the OR Society's Annual Conference and at meetings of the OR Society's Simulation Study Group (led by Stewart Robinson and Simon Taylor). Enough time has passed to look again at progress in this important field, and to consider its contribution to operational research and the wider academic community internationally.

The call for papers for this Special Issue yielded around thirty contributions from many diverse areas of the field. The rigorous referring process employed by the Journal led to the acceptance of fourteen of these. What emerged were two key strands of research: simulation modelling infrastructure and simulation modelling methodology. The papers in this issue are organised accordingly.

\section{Simulation Modelling Infrastructure}

Recent years have seen the development of important techniques that use networks of computers to transparently support simulation modelling. Four papers describe various advances in this field. Das reviews advances made in the use of multiple computers to speed up the execution of simulation models. Pooley and Wilcox investigate how remotely located simulation models can be distributed over the World Wide Web to support decision-making. Pidd and Cassel discuss the implications of the programming language Java for the development of simulation

Correspondence: SJE Taylor, Centre for Applied Simulation Modelling, Department of Information Systems and Computing, Brunel University, Uxbridge, UK.

Email: simon.taylor@brunel.ac.uk models. Finally, Gan and Turner consider the use of similar techniques in the simulation of virtual factories.

\section{Simulation Modelling Methodology}

The papers in this section describe advances in the area of simulation modelling methodology, that is, in the techniques used to create and analyse simulation models. What is apparent from these papers is the diversity of applications and perspectives on simulation modelling.

De Silva and Eglese consider the integration of simulation modelling and GIS in the context of evacuation planning. Moffat discusses the proper representation of command and control within models of conflict. Harding and Popplewell discuss the contribution that simulation modelling makes to the factory design process and enterprise design. Two papers concentrate on divergent aspects of the airline industry: Snowdon et al show how simulation can be applied to the improvement of airline passenger terminals, while Phillips and Marsh discuss how fast-time air traffic simulations may be validated. Within the health sector Eldabi et al develop an approach to the qualitative modelling of economic factors in adjuvant breast cancer treatment, and results from the valuation of screening services for diabetic retinopathy are represented by Davies et al. Barton and Tobias investigate the modelling of systems that contain discrete and continuous elements. Finally, the analysis of simulation models is considered in terms of optimisation by Ho et al and in terms of a methodology for interactive experimental design by Cheng and Lamb.

We hope that the reader finds the subjects covered in this special issue both stimulating and informative.

The Guest Editors: Simon JE Taylor, Stewart Robinson and Ray J Paul

\section{Reference}

1 Current Simulation Research Special Issue (1987). J Opl Res Soc 38: $671-774$. 